\title{
Anti-stigma campaigns: time to change
}

\author{
Michael Smith
}

\section{Summary}

This evaluation of the Time to Change anti-stigma campaign in England represents a milestone in international stigma research. While showing some positive outcomes, the overal picture is mixed and falls short of the wholesale shift in attitudes that is needed. A new approach is proposed for the coming decades.

\section{Declaration of interest}

M.S. is a member of the Management Group for 'see me', the scottish anti-stigma campaign, which is funded by the scottish Government.
Michael Smith is Associate Medical Director for Mental Health Services in NHS Greater Glasgow \& Clyde. He was a founding member of the Scottish anti-stigma campaign 'see me'.

'If you want truly to understand something, try to change it.'

Kurt Lewin

Elaine Cumming was a sociologist, and her husband John a psychiatrist. In 1951, they sought to change attitudes to mental illness by implementing a programme of community 'mental health education.' ${ }^{1}$ Based in a small prairie town in Canada, their pioneering anti-stigma programme used information leaflets, radio broadcasts, school programmes and engagement with community groups to convey to the townspeople three key principles about mental health. The first of these was that 'behaviour is caused, and therefore understandable and subject to change'; the second that 'there is a continuum between normality and abnormality'; and the third that 'there is a wider variety of normal behaviour than is generally realised'.

The project failed. The 'six-month educational program, in its all-out attempt to improve attitudes toward mental illness, produced virtually no change in the general orientation of the population either toward the social problem of mental illness or toward the mentally ill themselves.' ${ }^{1}$ Twenty-five years later, a replication study confirmed no change in attitudes. ${ }^{2}$

What went wrong? Contrary to expectations, townspeople accepted (or 'normalised') a broader range of behaviour than did the researchers. Lay people had their own explanations for human behaviour, which were rooted in their knowledge of peoples' life histories and which they were reluctant to reconsider. Most critically, the townspeople were convinced that there was a sharp dividing line between mental illness and normality and repelled efforts to change that view.

These findings have not dimmed the enthusiasm of professionals to 'educate' the public: quite the opposite. In 1996, the World Psychiatric Association launched its 'Open the Doors' campaign against the stigma of schizophrenia. Large-scale public campaigns followed in several countries: New Zealand ('Like Minds, Like Mine', 1997), Scotland ('see me', 2002); the USA ('What a Difference a Friend Makes', 2006), England ('Time to Change', 2007), Canada ('Opening Minds', 2009) and several others in Europe and elsewhere.

\section{Change is difficult}

The English Time to Change campaign consolidated much of this experience into a best practice model which targeted knowledge, attitudes and behaviour. The campaign was well funded (close to $£ 21$ million for the 4 years to 2011), led by major mental health charities, had clear objectives, and was subject to the rigorous evaluation published in this supplement. Separate papers describe the influence of the programme on employers, ${ }^{3}$ newspapers, ${ }^{4}$ medical students ${ }^{5}$ and the general public. ${ }^{6}$ This supplement also describes an economic evaluation, ${ }^{7}$ and the experience of discrimination by people using mental health services. ${ }^{8}$ The intervention and outcomes are summarised in the accompanying editorial by Henderson \& Thornicroft. ${ }^{9}$

The results reveal a mixed picture. Some parameters showed a positive change, such as a small reduction in discrimination reported by service users and improved employer recognition of common mental health problems. Some parameters showed an initial improvement which subsequently receded - confirming, for example, that improvements in medical students' attitudes are typically short lived.

Other measures did not change. Disappointingly, there was no improvement in knowledge or behaviour among the general public, nor in user reports of discrimination by mental health professionals. A few indicators showed a negative change over the study period, ironically including increased discrimination reported by those with most exposure to the Time to Change programme (albeit from survey response rates of only $6-8 \%$ ). It is not clear whether reports of increased discrimination represent a negative finding (due to adverse user experience) or a positive one (because users have greater awareness or confidence about speaking out).

Although economic analysis suggests a likely benefit from the programme, variation in the assumptions used in the model leaves a wide range of uncertainty: from a net cost to a benefit of $£ 223$ million.

\section{Increase the dose or change the treatment?}

The scale, coherence and rigour of this work is exemplary, and it represents a milestone in international stigma research. This evaluation comes at a time when campaigners are reflecting critically on the lessons learnt from similar campaigns in recent years. ${ }^{10}$ The fantasy shared (though rarely voiced) by many campaigners might have run something like this:

'if mental health workers truly have a model which is superior, and not just novel, this wonderful news will travel. When this happens, they will be invited into the community, as experts, to teach what they know, and they will find that the ranks have opened to welcome them. ${ }^{11}$

Sadly, that did not happen. We have made gains, not least in turning a 'non-issue' into an issue, but such change has been slow, patchy and vulnerable. This leaves anti-stigma campaigns with a 
critical strategic dilemma: do we increase the dose (more time, more advertising, more contact) or change the treatment? If the latter, what might such a change look like?

\section{Old lessons, new models}

Although defined in dictionaries as 'a mark of disgrace', stigma occurs in a complex mesh of relationships involving labelling, stereotyping, separation, status loss, discrimination and power imbalances. ${ }^{12}$ These processes occur at an individual level and in whole populations; affect some people with mental illness but not all; are poorly correlated with prejudicial attitudes ${ }^{13}$ and seem to disempower some individuals while energising others. ${ }^{14}$ Considered in this way, stigma is not really a 'mark' at all: it is a dynamic, relational process.

If so, it might be helpful to distinguish between stigma arising within individual relationships and that which emerges from whole populations. There are similarities here with economics. 'Macroeconomic' factors (such as unemployment and inflation) must be based on the 'microeconomic' decisions made in shops and workplaces. Yet 'macro' is not the same as more 'micro': economists recognise that new, 'emergent' properties arise from the complexity of interactions between the system components. ${ }^{15}$ It might be useful to think about stigma and discrimination in a similar way.

At the 'micro' level, researchers need to better understand the nature of the events that are reported as stigmatising. It is common, for example, for people who have harmed themselves to report stigmatising attitudes expressed by emergency department staff. ${ }^{16}$ Current conceptualisation of that adverse experience considers the shame felt by the service user, and presumes a deficit or dysfunction in the knowledge and attitudes of staff. It does not acknowledge the anger, frustration and despair brought to that consultation from outside, and is therefore blind to the potential for transference and countertransference reactions. The presumption of prejudice by staff does not permit an exploration of their perspective, which might include the defensive function of emotional distance from patients, or a fear of the medico-legal consequences of a wrong decision.

If stigma arises within relationships, we need to hear from both sides. We should be aware of the risk of 'stigmatising the stigmatiser' for behaviours that may be perceived as discriminatory, but which have complex origins that we need to understand.

These are not new insights. As the Cummings wrote 60 years ago: 'one of our errors [...] lay in our latent assumption that we knew the content of [...] people's attitudes toward human behaviour and its causes'. They recommended that future researchers should 'give attention to the function which these [bad] attitudes had for those who held them'. At the 'macro' level, our understanding of the ebb and flow of population attitudes and opinions is very limited. Worse, a complex adaptive system of this kind will tend to nullify intervention, evade investigation and confound interpretation. ${ }^{17}$ There is, therefore, much 'dark matter' influencing stigma at a population level that we still cannot see. The following analogy might apply:

'Let's say that we are trying to measure tide height at the beach. We know that the sea is filled with fish, and so we exhaustively model fish behaviour, developing complex models of their movements and interactions [...] The model is great. And the model is useless. The behaviour of the fish is irrelevant for the question we are interested in: how high will the seawater go up the beach? [...] we are focusing on the fish when we should be studying the moon.' (Cecchetti, quoted in Pettifor ${ }^{18}$ )
The work of Thornicroft and colleagues is impressive and reassuring, because they show that systematic, insightful and multifaceted campaigns can be implemented and tested at scale. But it also highlights a finding that we have to face up to: the wholesale shift in attitudes that we all want to see has yet to occur. We should resist the temptation to presume that 'more of the same' might work in future, since the Cummings remind us that we have been trying that now for 60 years. I hope that Time to Change can live up to its name and provoke a rethink not just for the public, but for anti-stigma campaigns as well.

Michael Smith, MD, FRCPsych, William Street Clinic, 120-130 William Street, Glasgow G3 8UR, UK. Email: michael.smith2@ggc.scot.nhs.uk

First received 25 Feb 2013, accepted 26 Feb 2013

\section{References}

1 Cumming E, Cumming J. Closed Ranks: An Experiment in Mental Health Education. Harvard University Press, 1957

2 Stuart H. Fighting stigma and discrimination is fighting for mental health. Can Publ Policy 2005; 31: s21-8.

3 Henderson C, Williams P, Little K, Thornicroft G. Mental health problems in the workplace: changes in employers' knowledge, attitudes and practices in England 2006-2010. Br J Psychiatry 2013; 202 (suppl 55): s70-6.

4 Thornicroft A, Goulden R, Shefer G, Rhydderch D, Rose D, Williams $P$, et al. Newspaper coverage of mental illness in England 2008-2011. Br J Psychiatry 2013; 202 (suppl 55): s64-9.

5 Friedrich B, Evans-Lacko S, London J, Rhydderch D, Henderson C, Thornicroft G. Anti-stigma training for medical students: the Education Not Discrimination project. Br J Psychiatry 2013; 202 (suppl 55): s89-94.

6 Evans-Lacko S, Henderson C, Thornicroft G. Public knowledge, attitudes and behaviour regarding people with mental illness in England 2009-2012. Br J Psychiatry 2013; 202 (suppl 55): s51-7.

7 Evans-Lacko S, Henderson C, Thornicroft G, Mccrone P. Economic evaluation of the Time to Change anti-stigma social marketing campaign in England 2009-2011. Br J Psychiatry 2013; 202 (suppl 55): s95-101.

8 Corker E, Hamilton S, Henderson C, Weeks C, Pinfold V, Rose D, et al. Experiences of discrimination among people using mental health services in England 2008-2011. Br J Psychiatry 2013; 202 (suppl 55): s58-63.

9 Evans-Lacko S, Henderson C, Thornicroft G, McCrone P. Economic evaluation of the Time to Change anti-stigma social marketing campaign in England 2009-2011. Br J Psychiatry 2013; 202 (suppl 55): s95-101.

10 Stuart H, Arboleda-Florez J, Sartorius N. Paradigms Lost: Fighting Stigma and the Lessons Learned: 304. Oxford University Press, 2012.

11 Siegier M, Osmond $\mathrm{H}$. 'Closed Ranks' twenty years later. Orthomolecular Psychiatry 1973; 2: 150-63.

12 Link BG, Phelan JC. Conceptualizing stigma. Ann Rev Sociology 2001; 27 363-85.

13 Schütz H, Six B. How strong is the relationship between prejudice and discrimination? A meta-analytic answer. Int J Intercult Relations 1996; 20 : 441-62.

14 Corrigan PW, Watson AC. The paradox of self-stigma and mental illness. Clin Psychol Sci Practice 2002; 9: 35-53.

15 Keen S. Debunking Economics (Revised and Expanded Edition): 472. Zed Books, 2011.

16 Hawton K, Taylor T, Saunders K, Mahadevan S. clinical care of deliberate self-harm patients: an evidence-based approach. In International Handbook of Suicide Prevention Research, Policy and Practice: 329-52. John Wiley \& Sons, 2011.

17 PIsek PE, Greenhalgh T. Complexity science: the challenge of complexity in health care. BMJ 2001; 323: 625-8.

18 Pettifor A. The power to 'create money out of thin air'. Open Democracy 2013; 18 January (http://www.opendemocracy.net/ourkingdom/ann-pettifor/ power-to-create-money-out-of-thin-air). 